\title{
A parameterisation for the activation of cloud drops including the effects of semi-volatile organics
}

\author{
P. J. Connolly ${ }^{1}$, D. O. Topping ${ }^{1}$, F. Malavelle ${ }^{2}$, and G. McFiggans ${ }^{1}$ \\ ${ }^{1}$ School of Earth, Atmospheric and Environmental Sciences, The University of Manchester, Manchester, UK \\ ${ }^{2}$ College of Engineering, Mathematics and Physical Sciences, University of Exeter, Exeter, UK
}

Correspondence to: P. J. Connolly (p.connolly@man.ac.uk)

Received: 3 May 2013 - Published in Atmos. Chem. Phys. Discuss.: 3 June 2013

Revised: 17 December 2013 - Accepted: 1 February 2014 - Published: 4 March 2014

\begin{abstract}
We present a parameterisation of aerosol activation, including co-condensation of semi-volatile organics, for warm clouds that has applications in large-scale numerical models. The scheme is based on previously developed parameterisations that are in the literature, but has two main modifications. The first is that the total aerosol mass is modified by the condensation of organic vapours entering cloud base, whereas the second is that this addition of mass acts to modify the median diameter and the geometric standard deviation of the aerosol size distribution. It is found that the scheme is consistent with parcel model calculations of cocondensation under different regimes. Such a parameterisation may find use in evaluating important feedbacks in climate models.
\end{abstract}

\section{Introduction}

The mean global radiative forcing associated with the indirect effect of aerosols on clouds is currently the most uncertain of those assessed by the Intergovernmental Panel on Climate Change (IPCC) (Solomon et al., 2007), having an uncertainty that is approximately the size of the total net anthropogenic radiative forcing. Increasing aerosol concentrations, possibly by anthropogenic activity, affect the radiative properties of stratocumulus (Sc) clouds by increasing the number of cloud drops in them, which increases the scattering of short-wave radiation (Twomey, 1977) and extends the lifetime of the cloud (Albrecht, 1989). This is thought to result in a cooling effect of approximately $-0.7 \mathrm{~W} \mathrm{~m}^{-2}$ globally.

Topping and McFiggans (2012) showed through calculation of the equilibrium between organic vapours and wa- ter vapour on pre-existing non-volatile aerosol that the organic vapour may act to significantly alter the non-volatile aerosol's ability to act as cloud condensation nuclei (CCN). Topping et al. (2013) confirmed this effect and quantified it under different aerosol and updraft regimes by performing detailed parcel model calculations of the diffusion of organic and water vapours to an aerosol population and assessed the effect this has on the activation of aerosol into cloud drops.

Kulmala et al. (2004) explain that such an effect may manifest as an important climate feedback mechanism, similar to that proposed by Charlson et al. (1987); however, the full "bin-microphysics" treatment used by Topping et al. (2013) is too computationally expensive for use within general circulation models (GCMs), which are the main tools used to calculate radiative forcing and climate feedbacks. The computational expense is also true for other large-scale atmospheric models. Hence, so that the effect proposed by Kulmala et al. (2004) may be assessed, our aim for this paper was to derive and test a parameterisation that captures the effect of semi-volatile co-condensation of organic vapours on the resulting number of cloud droplets. A parameterisation methodology was developed by Romakkaniemi et al. (2005) to represent the effect of co-condensation of nitric acid on cloud droplet activation. However, their approach is distinct from the approach described in this paper in that they empirically fitted multi-variate functions that describe activation. Our approach is to modify the framework of existing physically based parameterisations to take into account the effect of co-condensation.

Various physically based parameterisation schemes that determine the number of cloud droplets in warm clouds, and which do not take into account semi-volatile 
co-condensation, have been developed and used in GCMs. Two similar schemes are those proposed by Abdul-Razzak et al. (1998) and also by Fountoukis and Nenes (2005), which have been developed further since the original papers to include additional effects. These schemes have been shown to perform well (Ghan et al., 2011), and since they are physically based, there is the opportunity to develop them further to include the process that is the focus of this paper.

\section{Description of methodology}

The methodology that has been adopted in this paper is based on cloud activation schemes currently in the scientific literature - namely the schemes by Abdul-Razzak et al. (1998) and the later scheme by Fountoukis and Nenes (2005). A brief overview of both of these schemes is given here to provide the backdrop for the additions that we have made to include the effect of semi-volatile co-condensation.

\subsection{Basic scheme without co-condensation}

In formulating the scheme for activation, the assumption of an adiabatic parcel rising through an atmosphere in hydrostatic balance is made.

Central to both the above schemes is the assumption that the aerosol size distribution is distributed lognormally with respect to size:

$n_{\mathrm{ap}}\left(d_{\mathrm{ap}}\right)=\frac{N_{\mathrm{ap}}}{\sqrt{2 \pi} \ln \sigma} \exp \left[-\frac{\ln ^{2}\left(d_{\mathrm{ap}} / d_{\mathrm{m}}\right)}{2 \ln ^{2} \sigma}\right]$,

where $n_{\text {ap }}$ is the number of aerosols per unit volume, per logarithmic interval; $d_{\text {ap }}$ is the particle diameter; $\ln \sigma$ is the standard deviation of $\ln \frac{d_{\mathrm{ap}}}{d_{\mathrm{m}}} ; d_{\mathrm{m}}$ is the median diameter; and $N_{\mathrm{ap}}$ is the total number of particles per unit volume.

Both schemes introduce a change of variable, $S_{\text {crit }}=$ $\frac{2}{\sqrt{B}}\left(\frac{2 A}{3 d_{\mathrm{ap}}}\right)^{3 / 2}$, to Eq. (1) to give

$n_{\text {ap }}\left(S_{\text {crit }}\right)=\frac{2 N_{\text {ap }}}{3 S_{\text {crit }} \sqrt{2 \pi} \ln \sigma} \exp \left[-\frac{\ln ^{2}\left(\left[S_{\mathrm{c}, \mathrm{m}} / S_{\text {crit }}\right]^{(2 / 3)}\right)}{2 \ln ^{2} \sigma}\right]$,

where $S_{\mathrm{c}, \mathrm{m}}$ is the critical supersaturation of an aerosol with diameter equal to $d_{\mathrm{m}}$ and $S_{\text {crit }}$ is the critical supersaturation of an aerosol, diameter $d_{\mathrm{ap}}$.

The supersaturation, $S_{1}$, is given by $S_{1}=\frac{\left(e-e_{\mathrm{sat}, 1}\right)}{e_{\mathrm{sat}, \mathrm{l}}}$, so the rate of change is (quotient rule)

$\frac{d S_{1}}{d t}=\frac{1}{e_{\mathrm{sat}, 1}} \frac{d e}{d t}-\frac{e}{e_{\mathrm{sat}, \mathrm{l}}^{2}} \frac{d e_{\mathrm{sat}, 1}}{d t}$.

From the definition of vapour mixing ratio $w_{1}=\frac{\epsilon e}{P}$, we make $e$ the subject $\left(e=\frac{w_{1} P}{\epsilon}\right)$ and define the rate of change of vapour pressure (via product rule) for insertion into Eq. (3):

$\frac{d e}{d t}=\frac{1}{\epsilon} P \frac{d w_{\mathrm{v}}}{d t}+\frac{1}{\epsilon} w_{\mathrm{v}} \frac{d P}{d t}$.

For the second term on the right of Eq. (3) we make use of the Clausius-Clapyeron equation $\left(\frac{d e_{\text {sat, }}}{d T}=\frac{L_{\mathrm{v}} e_{\text {sat }}}{R_{\mathrm{v}} T^{2}}\right)$ :

$\frac{d e_{\mathrm{sat}, 1}}{d t}=\frac{d e_{\mathrm{sat}, 1}}{d T} \frac{d T}{d t}=\frac{L_{\mathrm{v}} e_{\mathrm{sat}}}{R_{\mathrm{v}} T^{2}} \frac{d T}{d t}$.

The rate of change of temperature can be expressed in terms of the rate of change of pressure and and phase of water via the first law of thermodynamics (time derivative):

$c_{\mathrm{p}} \frac{d T}{d t}-R_{\mathrm{a}} \frac{T}{P} \frac{d P}{d t}-L_{\mathrm{v}} \frac{d w_{1}}{d t}-L_{\mathrm{s}} \frac{d w_{\mathrm{i}}}{d t}=0$.

Therefore we substitute Eq. (6) into Eq. (5) and substitute the result and Eq. (4) into Eq. (3), resulting in

$$
\begin{aligned}
& \frac{d S_{1}}{d t}=\frac{1}{e_{\mathrm{sat}, 1}}\left(\frac{1}{\epsilon} P \frac{d w_{\mathrm{v}}}{d t}+\frac{1}{\epsilon} w_{\mathrm{v}} \frac{d P}{d t}\right) \\
& -\frac{e}{e_{\mathrm{sat}, 1}} \frac{L_{\mathrm{v}}}{R_{\mathrm{v}} T^{2}}\left(\frac{R_{\mathrm{a}} T}{c_{\mathrm{p}} P} \frac{d P}{d t}+\frac{L_{\mathrm{v}}}{c_{\mathrm{p}}} \frac{d w_{1}}{d t}+\frac{L_{\mathrm{s}}}{c_{\mathrm{p}}} \frac{d w_{\mathrm{i}}}{d t}\right) .
\end{aligned}
$$

Noting that Eq. (7) depends on the rate of change of pressure we take the time derivative of the hydrostatic relation for the parcel

$\frac{d P}{d t}=-\frac{g P}{R_{\mathrm{a}} T} w$,

(where $w$ is the vertical wind speed) and substitute Eq. (8) into Eq. (7):

$$
\begin{aligned}
& \frac{d S_{1}}{d t}=\left(S_{1}+1\right)\left[\left(\frac{g L_{\mathrm{v}}}{c_{\mathrm{p}} R_{\mathrm{v}} T^{2}}-\frac{g}{R_{\mathrm{a}} T}\right) w\right. \\
& \left.-\left(\frac{1}{w_{\mathrm{v}}}+\frac{L_{\mathrm{v}}^{2}}{R_{\mathrm{v}} T^{2} c_{\mathrm{p}}}\right) \frac{d w_{1}}{d t}-\left(\frac{1}{w_{\mathrm{v}}}+\frac{L_{\mathrm{v}} L_{\mathrm{s}}}{R_{\mathrm{v}} T^{2} c_{\mathrm{p}}}\right) \frac{d w_{\mathrm{i}}}{d t}\right],
\end{aligned}
$$

where we have also used the fact that total water in the parcel is conserved and have neglected the ice phase:

$$
\frac{d w_{\mathrm{v}}}{d t}+\frac{d w_{1}}{d t}+\frac{d w / 1}{d t}=0 .
$$

For cloud droplet activation, it is the peak in $S_{1}$ that is important in determining how many aerosols are activated into cloud drops. The peak in supersaturation is the stationary point of Eq. (9), which is located at $\frac{d S_{1}}{d t}=0$ :

$0=\left(\frac{g}{c_{\mathrm{p}}}-\frac{g}{R_{\mathrm{a}} T}\right) w-\left(\frac{1}{w_{\mathrm{v}}}+\frac{L_{\mathrm{v}}^{2}}{R_{\mathrm{v}} T^{2} c_{\mathrm{p}}}\right) \frac{d w_{1}}{d t}$.

The quantity $\frac{d w_{1}}{d t}$ is dependent on the supersaturation and how it varies in time up to the supersaturation peak. The reason for this is that the supersaturation time history determines 
the size of the droplets, which requires an integral to be evaluated, and the size of the droplets determines the instantaneous rate of change of supersaturation. Both Abdul-Razzak et al. (1998) and Fountoukis and Nenes (2005) schemes define different forms of the integral to be evaluated; however, both depend on the peak in supersaturation and the properties of the aerosol particle size distribution.

The mass growth rate of drops is described by a growth equation first derived by Maxwell:

$\frac{d m}{d t} \cong 2 \pi d G \rho_{\mathrm{w}} S_{1}$,

where $d$ is the diameter of a drop and $G$ is a thermodynamic factor.

Diameter growth rates follow a quadratic law found by making the change of variable $m=\frac{\pi}{6} d^{3} \rho_{\mathrm{w}}$ to Eq. (11) and integrating

$\frac{d d}{d t}=\frac{G S_{1}}{d}$

which yields

$d(t)^{2}=d_{\text {crit }}^{2}+2 G \int_{\tau=S_{\text {crit }}}^{t\left(S_{\max }\right)} S_{1}\left(t^{\prime}\right) d t^{\prime}$,

where $\tau$ is the time at which the critical supersaturation is reached.

To find $\frac{d w_{1}}{d t}$ at the critical supersaturation in Eq. (10), Eq. (13) is substituted into Eq. (11), which is multiplied by Eq. (2) and integrated between 0 and $S_{\max }$. This yields

$\frac{d w_{1}}{d t}=2 \pi \rho_{\mathrm{w}} G S_{1} \int_{0}^{S_{1}}\left[d\left(S^{\prime}\right)^{2}+2 G \int_{S^{\prime}}^{t\left(S_{\max }\right)} S\left(t^{\prime}\right) d t^{\prime}\right]^{1 / 2} n_{\mathrm{ap}}\left(S^{\prime}\right) d S^{\prime}$.

The difference between the Abdul-Razzak et al. (1998) and the Fountoukis and Nenes (2005) schemes are in the estimation of Eq. (14). Abdul-Razzak et al. (1998) use an approximation for the second term by Twomey (1959) to formulate an analytical expression, which is dependent on $S_{\max }$. This is then substituted into Eq. (10) and rearranged for $S_{\max }$. Fountoukis and Nenes (2005) assume that the aerosol size distribution consist of two populations, one of swollen aerosol and one of activated aerosol. They also approximate the integral, but in such a way that $S_{\max }$ cannot be isolated when substituted into Eq. (10), and hence $S_{\max }$ is found by iteration. For details the reader is directed to the respective papers.

\subsection{Inclusion of co-condensation in the parameterisation}

A simple modification that can be made to either of the above schemes to take account of condensed semi-volatile vapours during activation is to alter the Köhler curve parameters (such as the aerosol density, van't Hoff factors and molecular masses) and the size distribution parameters $\left(N_{\mathrm{ap}}\right.$, $\ln \sigma$ and $d_{\mathrm{m}}$ ) so that the total aerosol mass is equal to the sum of the non-volatile aerosol mass and the mass of condensed organics. Total aerosol particle number concentration is unaffected by condensation, so parameters of the aerosol size distribution that may be changed are the geometric standard deviation and the median diameter of the distribution. Once these parameters have been found, either of the two schemes can be adopted as is to calculate the activated fraction.

\subsubsection{Determining the amount of condensed organic vapour}

Results presented by Topping et al. (2013) (their Fig. 2) showed that, under certain situations, the majority of semivolatile organic vapour at cloud base is in the condensed phase. Their Fig. 2 was for an aerosol median diameter equal to $150 \mathrm{~nm}$ and particle concentrations in the range of $\sim 500 \mathrm{~cm}^{-3}$. Using the same model as Topping et al. (2013) we have extended these computations for different updraft speeds and aerosol size distributions and present a summary of the findings in Fig. 1. Figure 1 shows that not all semivolatile organic mass is condensed at cloud base for low aerosol particle concentrations and for low aerosol particle median diameters. To overcome this difficulty we have implemented an RH- and size-dependent, molar-based partitioning model for secondary organic aerosol (McFiggans et al., 2010) to enable the calculation of the condensed semivolatile mass at cloud base.

However, Fig. 1 also shows that, at high updraft speeds, we cannot assume that the semi-volatile vapours are in equilibrium at cloud base: the rate of diffusion of the organic vapours to the particles is too low. Hence, this paper will test the impact of the assumption of equilibrium for the partitioning of semi-volatiles on the calculation of the activated fraction entering clouds.

\subsubsection{Two methods of initialisation}

We performed two distinct methods of initialisation for the aerosol size/composition distribution. The first method initialised a "core" aerosol particle size distribution with the specified lognormal distribution parameters (total number concentration, $N_{\mathrm{ap}}$; median diameter, $d_{\mathrm{m}}$; and geometric standard deviation, $\ln \sigma$ ) onto which the semi-volatiles condense. This method is assumed to be the most appropriate initialisation in a model that does not explicitly solve growth equations for the condensation of semi-volatile organics onto the aerosol particles. During the activation of cloud drops, the semi-volatiles were then assumed to condensed onto the aerosol particle distribution and thus shift the median diameter and geometric standard deviation (see Sect. 2.2.3).

We performed model runs setting the geometric standard deviation, $\ln \sigma$, and the median diameter, $d_{\mathrm{m}}$, were set to 0.5 and $60 \mathrm{~nm}$ respectively, while four different simulations 

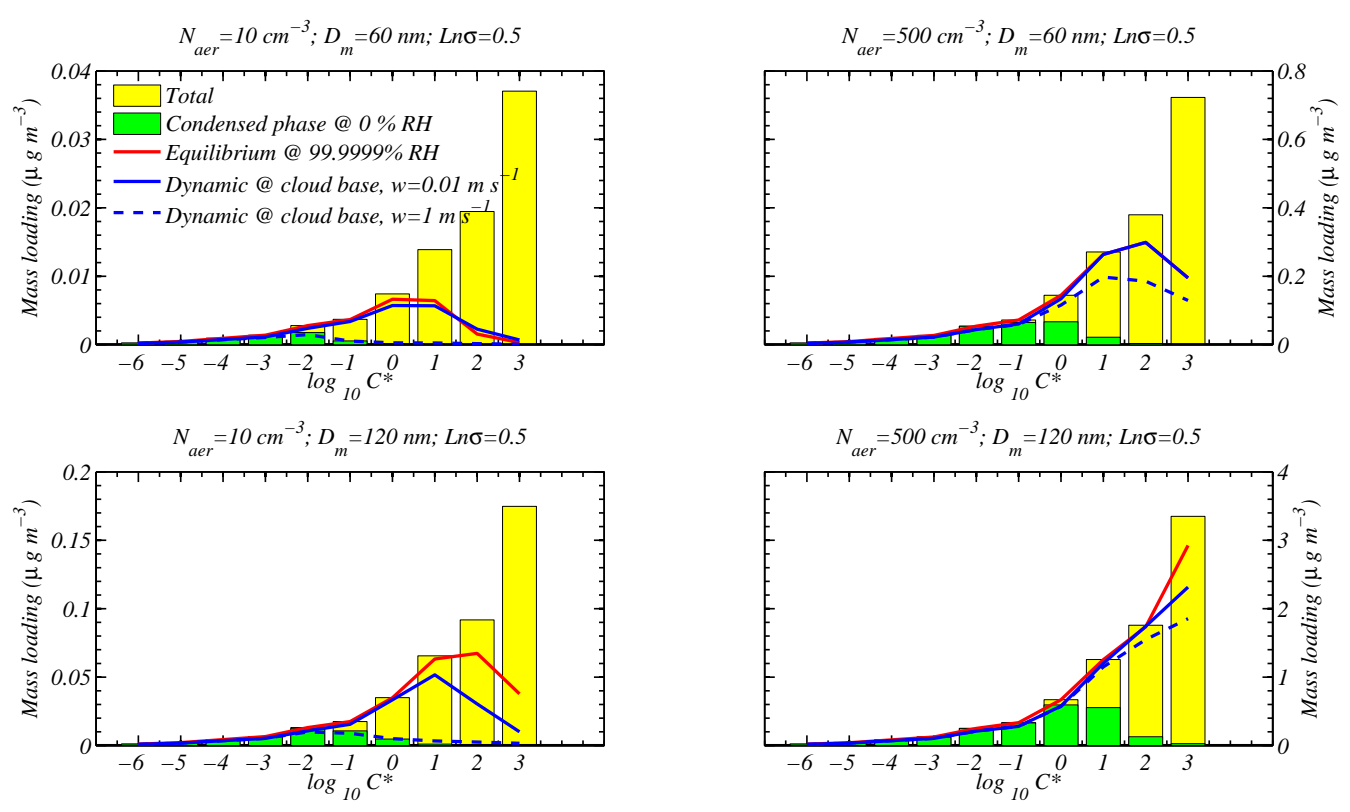

Fig. 1. Top panels show the concentration of total semi-volatiles and those that condensed at $0 \% \mathrm{RH}$, as well as equilibrium and dynamical calculations for the condensed semi-volatile content at cloud base for a slow updraft and the dynamical calculation of the condensed semivolatile content for a faster updraft speed $\left(d_{\mathrm{m}}=60 \mathrm{~nm}\right)$. The left column is for low aerosol concentrations, whereas the right is for higher aerosol concentrations. Bottom panels show the same as the top, but for the aerosol size distribution with $d_{\mathrm{m}}=120 \mathrm{~nm}$.

were performed for different total aerosol number concentrations, $N_{\text {ap }}=[10,100,500,1000] \mathrm{cm}^{-3}$ and a total semivolatile content of $1.89 \mathrm{\mu g} \mathrm{m}^{-3}$.

The results show that, for updraft speeds that are lower than those typically found in trade-wind cumulus $(\mathrm{Cu})$ clouds (see Section 3.3), the assumption that most of the organic vapour condenses at cloud base is a reasonable approximation for aerosol concentrations higher than $\sim 100 \mathrm{~cm}^{-3}$, as we now elaborate on. Figure 2a shows the amount of organic vapour in the simulation as a function of temperature for a constant updraft speed of $0.1 \mathrm{~m} \mathrm{~s}^{-1}$. Here, cloud base is situated around $292.1 \mathrm{~K}$ and it can be seen that almost all of the organic vapour condenses onto the aerosol size distribution as it enters cloud. Figure $2 \mathrm{~b}$ shows the same except for an updraft speed of $2.0 \mathrm{~m} \mathrm{~s}^{-1}$. In this plot it is seen that the lower aerosol concentrations result in less condensation by virtue of there being less competition for the organic vapours, as well as the finite time required for vapour diffusion. For aerosol concentrations higher than $500 \mathrm{~cm}^{-3}$, at cloud base, $\sim 15 \%$ of the organic vapours are still to condense, and this fraction increases as the aerosol particle concentration decreases. For example, for aerosol particle concentrations of $100 \mathrm{~cm}^{-3}, 70 \%$ of the vapours are still to condense, and for particle concentrations of $10 \mathrm{~cm}^{-3}$ this results in $95 \%$ still to condense. Thus, at high updraft speeds and low aerosol concentrations it appears that the organic vapours are not in equilibrium. However, at these high updraft speeds and low aerosol concentrations, nearly all of the aerosol will act as $\mathrm{CCN}$ in any case, even without the full condensation of semi- volatiles; hence, the validity of assuming equilibrium of the semi-volatiles at cloud base needs to be evaluated with respect to the predicted droplet number concentration. This is done in Sect. 3.2.2.

The second method was to specify the mass-weighted composition of the aerosol at the start of the simulation such that, at the start of the simulation, the aerosols are in equilibrium with the semi-volatile organics and the resulting distribution has the specified lognormal distribution parameters. This required the total concentration in each volatility bin to be scaled (up or down) so that the desired massweighted composition was achieved (as described by Topping et al., 2013). We then allow the semi-volatile organics to condense onto the aerosol particles during their ascent to cloud base. This type of initialisation implies smaller aerosol particles at cloud base than the first initialisation because the specified lognormal parameters refer to particles that already have a fraction of the semi-volatiles condensed onto them. For the second type of initialisation we specified an initial mass-weighted composition of condensed semi-volatiles to be $90 \%$. We show the condensed fraction in the highest 3 volatility bins, at cloud base, in Fig. 3. The results show that the assumption that the condensed fraction is equal to the equilibrium value does not hold in general. At low updraft speeds the assumption of equilibrium holds reasonably well, but is also a function of the number concentration of aerosol particles. Low concentrations result in significant deviations from equilibrium. Hence, we evaluate the impact of assuming equilibrium of the semi-volatile organics 
on the activated fraction for the second type of initialisation in Sect. 3.2.2.

\subsubsection{Altering the lognormal distribution}

The addition of organic material to the aerosol size distribution adds mass to the total aerosol burden, but does not alter the number of aerosol particles. This has the effect of increasing the median diameter, $d_{\mathrm{m}}$, and altering the geometric standard deviation, $\ln \sigma$. The constraint of total aerosol mass (a single constraint) is insufficient to determine both $d_{\mathrm{m}}$ and $\ln \sigma$ (two parameters), so a method to close the parameterisation was sought. To investigate ways of doing this we first used the parcel model described by Topping et al. (2013) to investigate how the geometric standard deviation changed following co-condensation of organic vapour.

Both the non-volatile aerosol distribution and the aerosol size distribution following co-condensation at cloud base (note this is the effective aerosol distribution without the associated water) are shown in Fig. 4, which shows that the geometric standard deviation decreases substantially following the condensation of organic vapours. The green dashed lines on the plot show the original non-volatile aerosol particle distribution but shifted to the right by a constant factor. This shows that there is good agreement between the shape of a non-volatile aerosol particle distribution, which is shifted by a constant along the diameter axis, and the final distribution onto which the vapours have condensed. This therefore implies that the arithmetic standard deviation of the aerosol particle distribution is approximately invariant before and after condensation of the organic vapours. This is demonstrated in Fig. 5, where the same aerosol distributions are plotted on a linear diameter axis. The appendix provides arguments as to why the arithmetic standard deviation of the "dry" aerosol distribution does not change following co-condensation. Note that this finding is also true for the $60 \mathrm{~nm}$ median diameter particles (not shown).

In order to determine how the geometric standard deviation changed, we used the definition of the arithmetic standard deviation, SD, of a lognormal distribution (see http: //en.wikipedia.org/wiki/Log-normal_distribution):

$S D=\exp \left(\ln d_{\mathrm{m}}+\frac{1}{2} \ln ^{2} \sigma\right) \sqrt{\exp \left(\ln ^{2} \sigma\right)-1}$.

Equation (15), with the assumption that SD stays the same before and after co-condensation, allows us to calculate the geometric standard deviation after co-condensation; we do this in the following way. Firstly we compute the arithmetic standard deviation for the initial aerosol particle distribution, which becomes the constraint for the distribution after cocondensation towards cloud base. Secondly we compute the new total aerosol mass, $m_{\text {tot }}$, by adding the additional semivolatile mass at cloud base (determined by molar-based partitioning) to the initial aerosol distribution. The density of the aerosol, $\rho_{\text {ap }}$, is assumed to be constant over the whole distri- bution and is calculated using an appropriate mixing rule:

$\frac{m_{\text {tot }}}{\rho_{\text {ap }}}=\Sigma_{\mathrm{i}} \frac{m_{\mathrm{i}}}{\rho i}$.

A root-finding method is used to alter the $d_{\mathrm{m}}$ of the aerosol distribution following condensation of the organic vapour, from which the corresponding geometric standard deviation is calculated by root-finding Eq. (15), with SD set to the arithmetic standard deviation of the initial aerosol distribution. This is done until the total mass in the aerosol size distribution, found using an expression for the third moment of a lognormal distribution, is equal to $m_{\text {tot }}$. It should be noted that changing the geometric standard deviation in this way is a crucial step in the scheme (see Section 3.2).

\section{Performance of scheme}

\subsection{Framework to test scheme}

An adiabatic framework was used to test the scheme. This framework is given an initial $\mathrm{RH}=0.95, T=293.15$ and $P=950 \mathrm{hPa}$, as well as organic vapour concentrations (taken from Cappa and Jimenez, 2010), we derived the values of $T$ and $P$ at cloud base and applied the parameterisation for those conditions. The calculation of cloud base $T$ and $P$ was as follows. Firstly, the temperature of cloud base was determined by root-finding the temperature at which the initial water vapour pressure is equal to the saturation vapour pressure. Secondly, the cloud-base pressure was determined by conserving dry potential temperature. Although strictly one should take in to account the effects of moist air on the gas constant and the heat capacity of the air, neglecting this results in very little difference to the calculated cloud-base pressure.

In order to assess the performance of the scheme we compare it against a parcel model with bin microphysics, which is described by Topping et al. (2013). The parcel model was run for for aerosol lognormal parameters $\ln \sigma=0.5, d_{\mathrm{m}}=60 \mathrm{~nm}$ and for $N_{\mathrm{ap}}=[10,100,500,1000] \mathrm{cm}^{-3}$ and run for eight different updraft velocities: $0.01,0.1,0.5,1.0,2.0,5.0,8.0$ and $10.0 \mathrm{~m} \mathrm{~s}^{-1}$. This was done for both with and without cocondensation of organic vapours. As described in Sect. 2.2.2, there were two types of initial condition: (i) initialisation with a "core" mode of ammonium sulfate aerosol of specified median and geometric standard deviation upon which condensation of semi-volatile organic vapours having a total mass loading of $1.89 \mu \mathrm{g} \mathrm{m}^{-3}$ with a distribution specified by Cappa and Jimenez (2010) was allowed to occur, and (ii) initialisation with an aerosol that has a composition of $90 \%$ semi-volatile by mass at a relative humidity of $0 \%$, which necessitated scaling the total mass loading of semi-volatiles by a factor of between $\sim 0.05$ and $\sim 7$, depending on the concentration of aerosol particles and the median diameter. For the latter runs we also investigated the effect of separately increasing the median diameter to $120 \mathrm{~nm}$ and increasing $\ln \sigma$ 

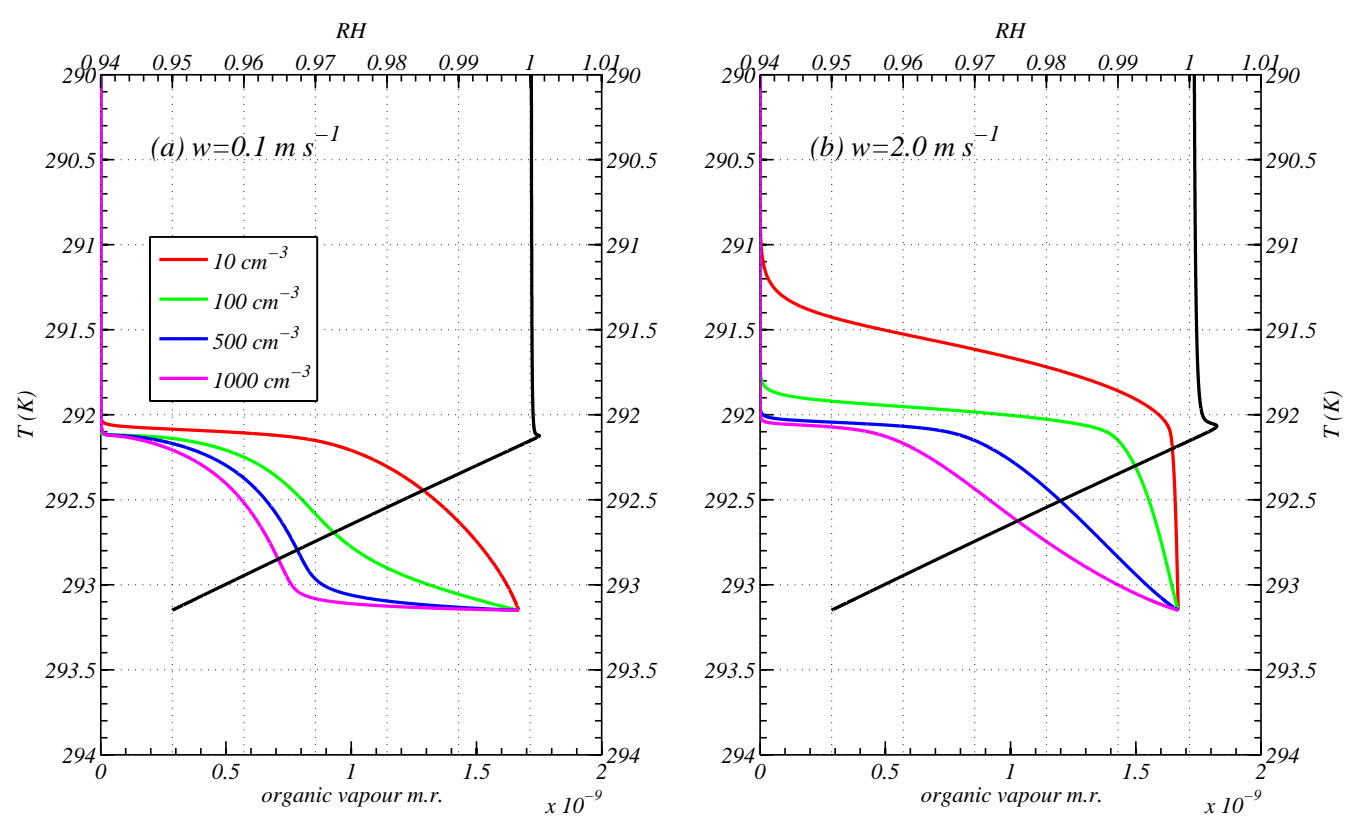

Fig. 2. (a) shows the organic vapour content in the parcel plotted against temperature (coloured lines) for parcel model simulations assuming an updraft speed of $0.1 \mathrm{~m} \mathrm{~s}^{-1}$. The different coloured lines correspond to parcel model simulations that contain different total aerosol number concentrations (as in the legend). The black line is the humidity for the simulation with $1000 \mathrm{~cm}^{-3}$ aerosol particles. (b) is the same as for (a) but for an updraft velocity of $2.0 \mathrm{~m} \mathrm{~s}^{-1}$
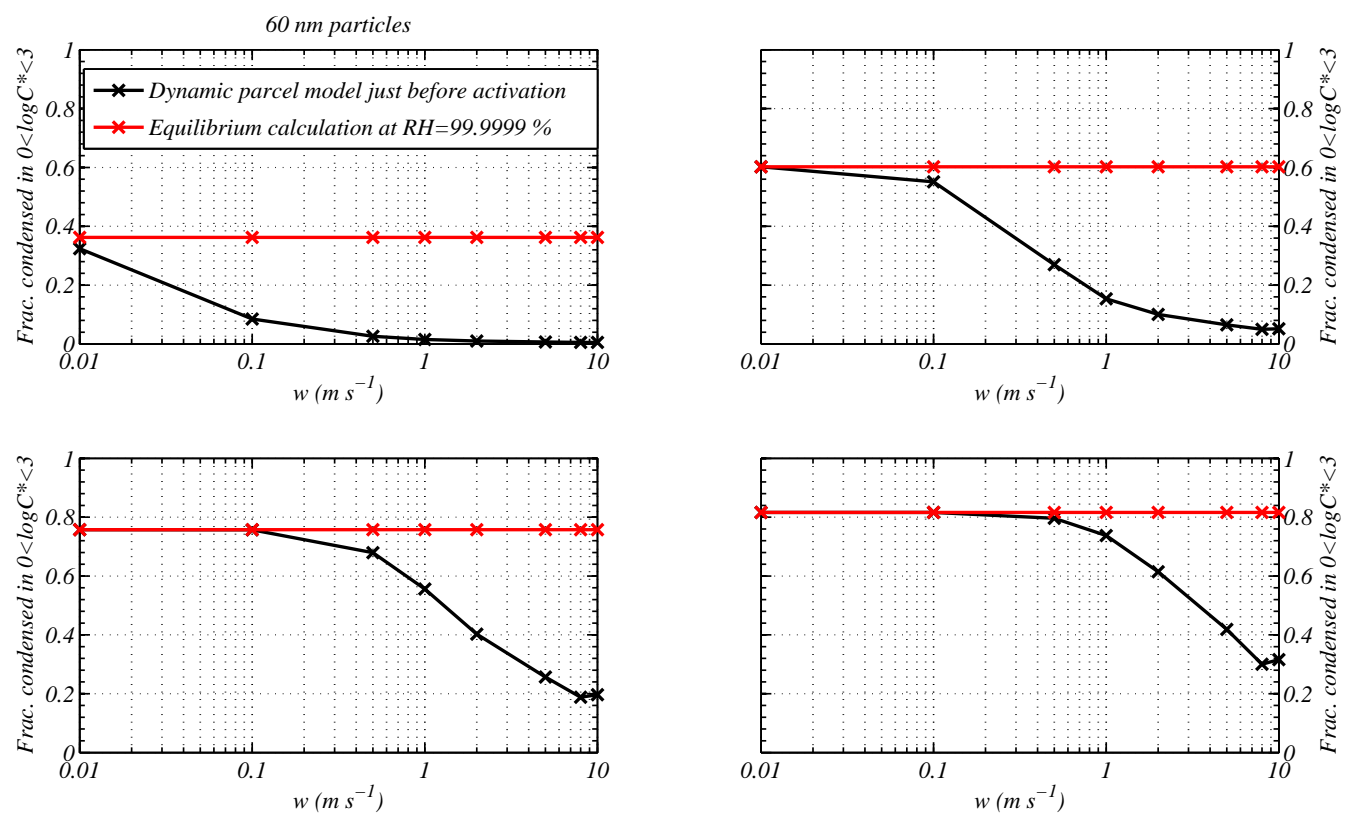

Fig. 3. Shows the fraction of condensed semi-volatiles in $1 \leq C^{*} \leq 1000 \mu \mathrm{g} \mathrm{m}{ }^{-3}$ bins for the size distribution with parameters log $\sigma=0.5$ and $d_{\mathrm{m}}=60 \mathrm{~nm}$. Top left is for $N_{\mathrm{ap}}=10 \mathrm{~cm}^{-3}$, top right is for $N_{\mathrm{ap}}=100 \mathrm{~cm}^{-3}$, bottom left is for $N_{\text {ap }}=500 \mathrm{~cm}^{-3}$ bottom right is for $N_{\text {ap }}=1000 \mathrm{~cm}^{-3}$

from 0.5 to 0.6 . This gave a set of 64 parcel model runs for the first initialisation. There were a further $64 \times 3$ runs for the second initialisation (i.e. 64 runs each for $d_{\mathrm{m}}=60 \mathrm{~nm}$, $d_{\mathrm{m}}=120 \mathrm{~nm}$ and $\ln \sigma=0.6$ runs). Thus, there are 256 parcel model simulations presented in total. 

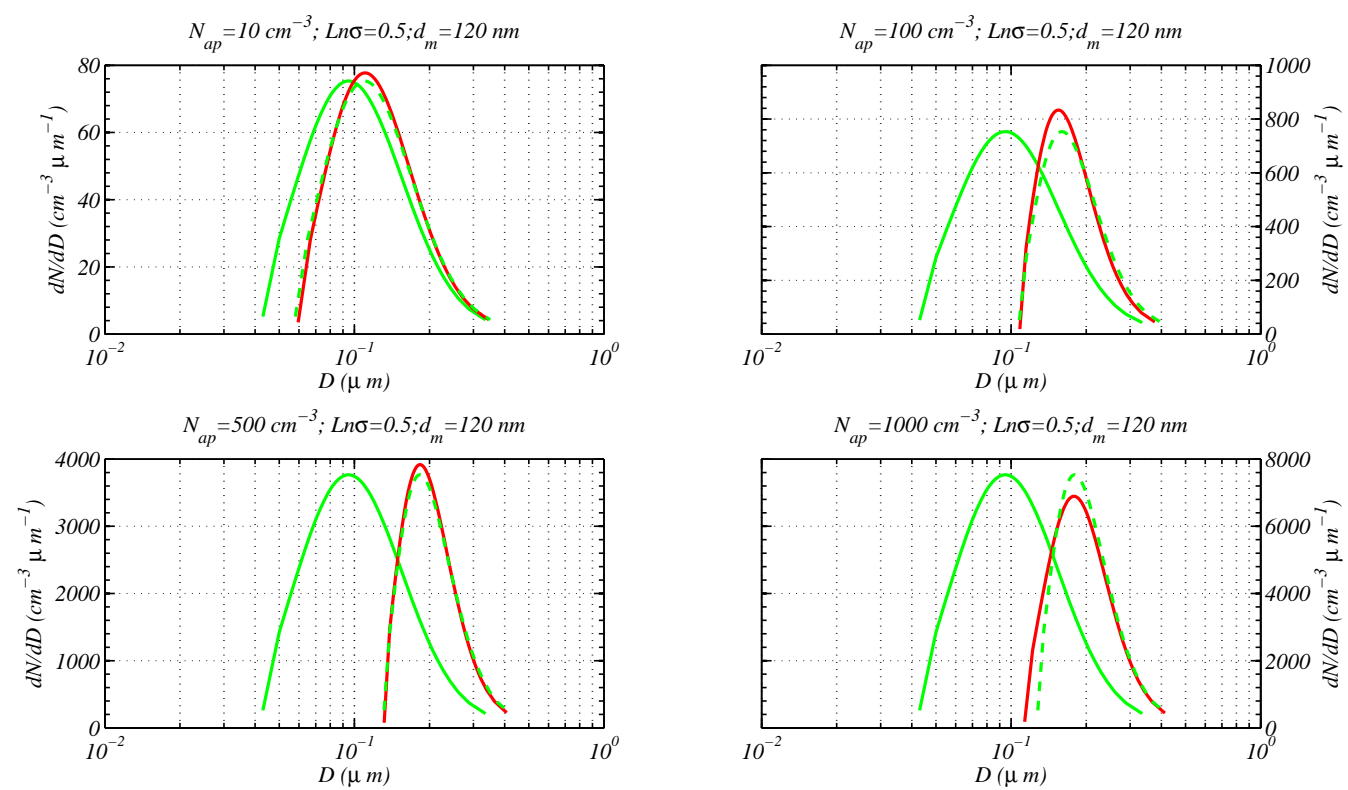

Fig. 4. Particle size distributions before and after co-condensation just below cloud base. Top left is for total aerosol concentration of $10 \mathrm{~cm}^{-3}$, top right is for $100 \mathrm{~cm}^{-3}$, bottom left is for $500 \mathrm{~cm}^{-3}$ and bottom right for $1000 \mathrm{~cm}^{-3}$. The green solid line is the aerosol particle distribution with a semi-volatile content equal to the $0 \% \mathrm{RH}$ equilibrium value, whereas the red solid line is the aerosol particle distribution after further co-condensation of semi-volatiles (this excludes the liquid water, so is only the effective "dry" aerosol size). The green dashed line is the original aerosol size distribution that has been shifted in diameter space by a constant factor. These aerosol size distributions are plotted on a logarithmic scale for the diameter.
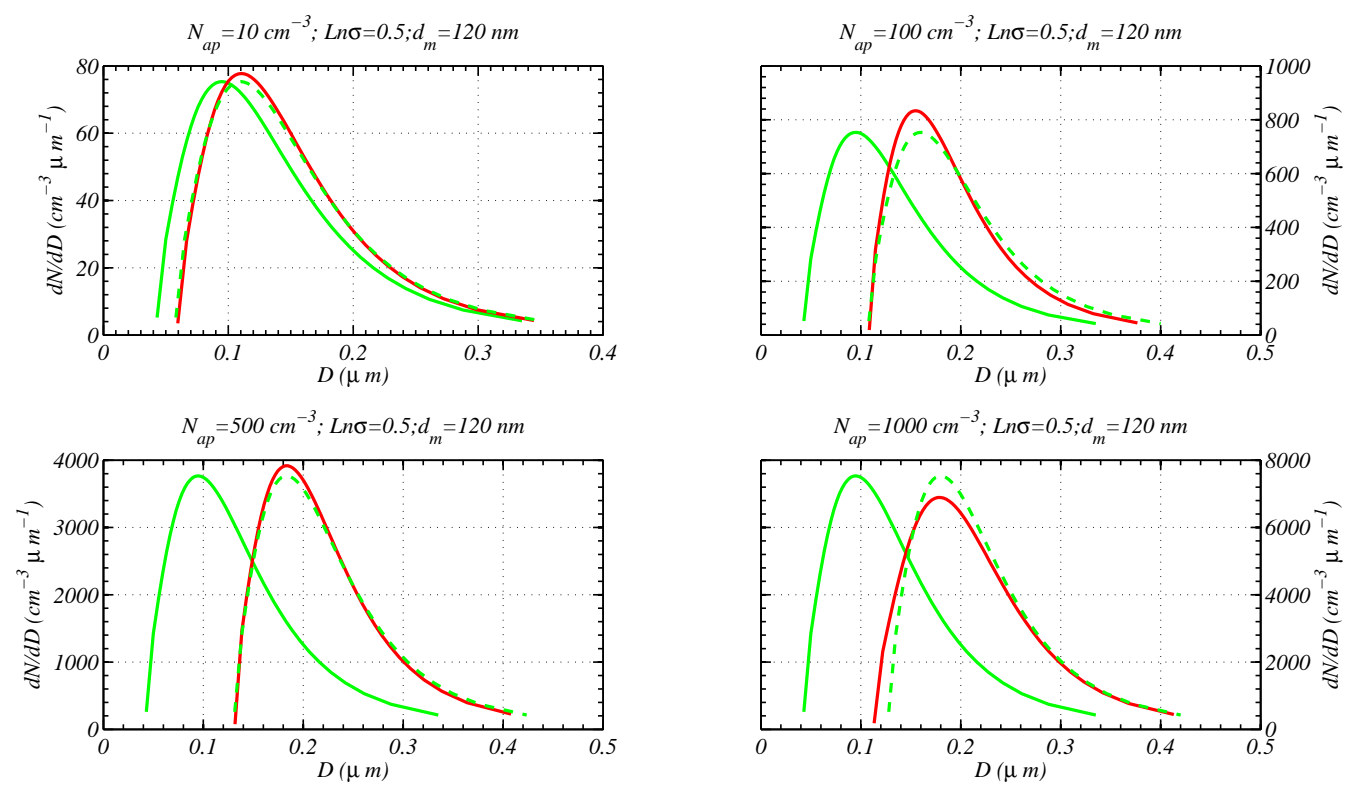

Fig. 5. Same as Fig. 4 but plotted on a linear scale for the diameter.

\subsection{Comparison for different aerosol distributions}

To compare the schemes with the parcel model, we varied the aerosol particle concentration in the initial aerosol size distribution, looking at total number concentrations ranging from 10 to $1000 \mathrm{~cm}^{-3}$ as described above. We performed calcula-

tions using the parameterisation for a range of updraft velocities from 0.01 to $10 \mathrm{~m} \mathrm{~s}^{-1}$ both with and without the effect of co-condensation of organic vapour. 

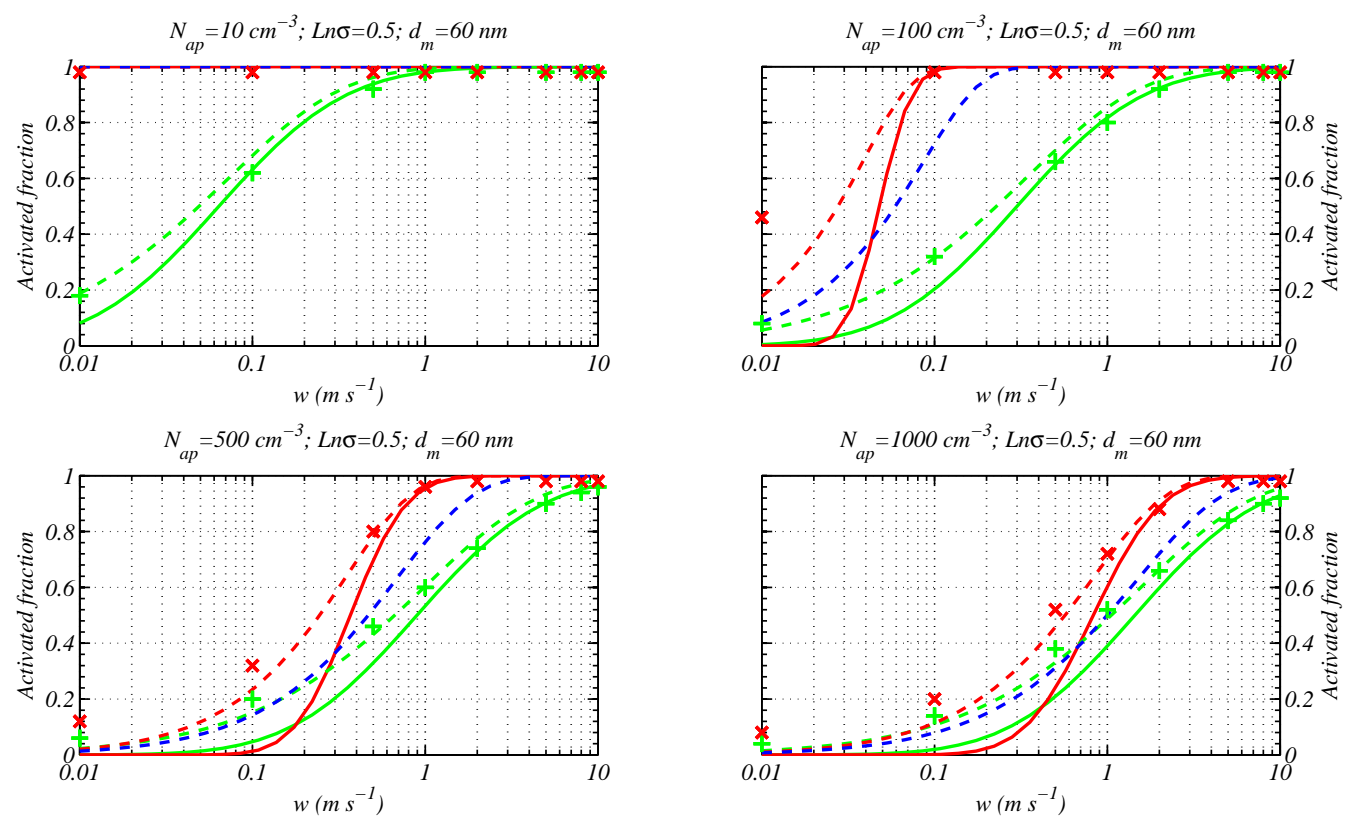

Fig. 6. Comparisons using the "first" type of initialisation (see Section 2.2.2): red and green solid lines show the parcel model with the Abdul-Razzak et al. (1998) implementation for both with and without semi-volatile co-condensation; red and green dashed lines show the same, but for the Fountoukis and Nenes (2005) implementation; and the blue lines are for the Fountoukis and Nenes (2005) implementation, but without the maintenance of arithmetic standard deviation. Top left is for $10 \mathrm{~cm}^{-3}$ total aerosol, top right is for $100 \mathrm{~cm}^{-3}$, bottom left is $500 \mathrm{~cm}^{-3}$ and bottom right is for $1000 \mathrm{~cm}^{-3}$. Crosses are the parcel model results and lines are the parameterisation. Green lines for without semi-volatile condensation and red (and blue) with.

\subsubsection{First type of initialisation}

For the first type of initialisation (see Sect. 2.2.2), Fig. 6 (solid lines) shows the comparison between the parcel model and the parameterisation implemented via the Abdul-Razzak et al. (1998) scheme. It shows that, while the addition of the co-condensation parameterisation improves the agreement at higher updraft speeds $\left(w>\sim 0.5 \mathrm{~m} \mathrm{~s}^{-1}\right)$, it does not perform very well at lower updraft speeds $\left(w<\sim 0.5 \mathrm{~m} \mathrm{~s}^{-1}\right)$. In fact, the parcel model shows that semi-volatile co-condensation serves to enhance droplet number concentrations across the range of updraft speeds for all choices of $N$, whereas the parameterisation using the Abdul-Razzak et al. (1998) scheme shows that this is reversed at low updraft speeds.

Figure 6 (dashed green and red lines) shows the results of the parameterisation implemented using the Fountoukis and Nenes (2005) scheme. This shows that there is no dramatic "crossover" (where the co-condensation-activated fraction goes from being higher to lower than the standard scheme) in the activated fraction for with and without semi-volatile cocondensation. For example, this crossover effect occurs in the Abdul-Razzak et al. (1998) scheme at a vertical winds of $w=$ $0.03,0.2$ and $0.4 \mathrm{~m} \mathrm{~s}^{-1}$ in the 100,500 and $1000 \mathrm{~cm}^{-3}$ simulations respectively. Therefore the Fountoukis and Nenes (2005) implementation of the parameterisation is more consistent with the parcel model. Although it is not a perfect comparison - for example, it still underestimates the acti- vated fraction at low updraft speeds - it does show good general agreement over a range of conditions.

In order to demonstrate how important the shifting of the geometric standard deviation is, we have compared the parameterisation scheme using the Fountoukis and Nenes (2005) scheme, but without shifting the geometric standard deviation (as described in Sect. 2.2.3); hence, we kept the $\ln \sigma$ the same in the parameterisation after equilibration of semi-volatile organics at cloud base. This comparison is shown in Fig. 6 (blue dashed lines to compare to red crosses) and demonstrates that the reduction in $\ln \sigma$ is a main factor in enhancing the activated fraction in this particular case. It is evident that not reducing $\ln \sigma$ results in an underestimation of the activated fraction (compare Fig. 6 blue lines to red dashed lines and crosses) for all updraft speeds, and this is especially evident when aerosol number concentrations are high.

\subsubsection{Second type of initialisation}

We now show results from the "second" type of initialisation (described in Sect. 2.2.2). Since we established that the Abdul-Razzak et al. (1998) scheme underestimates at low updraft speeds, we now only show comparisons for the Fountoukis and Nenes (2005) scheme.

Figure 7 shows the results for an aerosol size distribution with initial parameters equal to $d_{\mathrm{m}}=60 \mathrm{~nm}$ and $\ln \sigma=0.5$. It is shown that the scheme does a good job for aerosol 

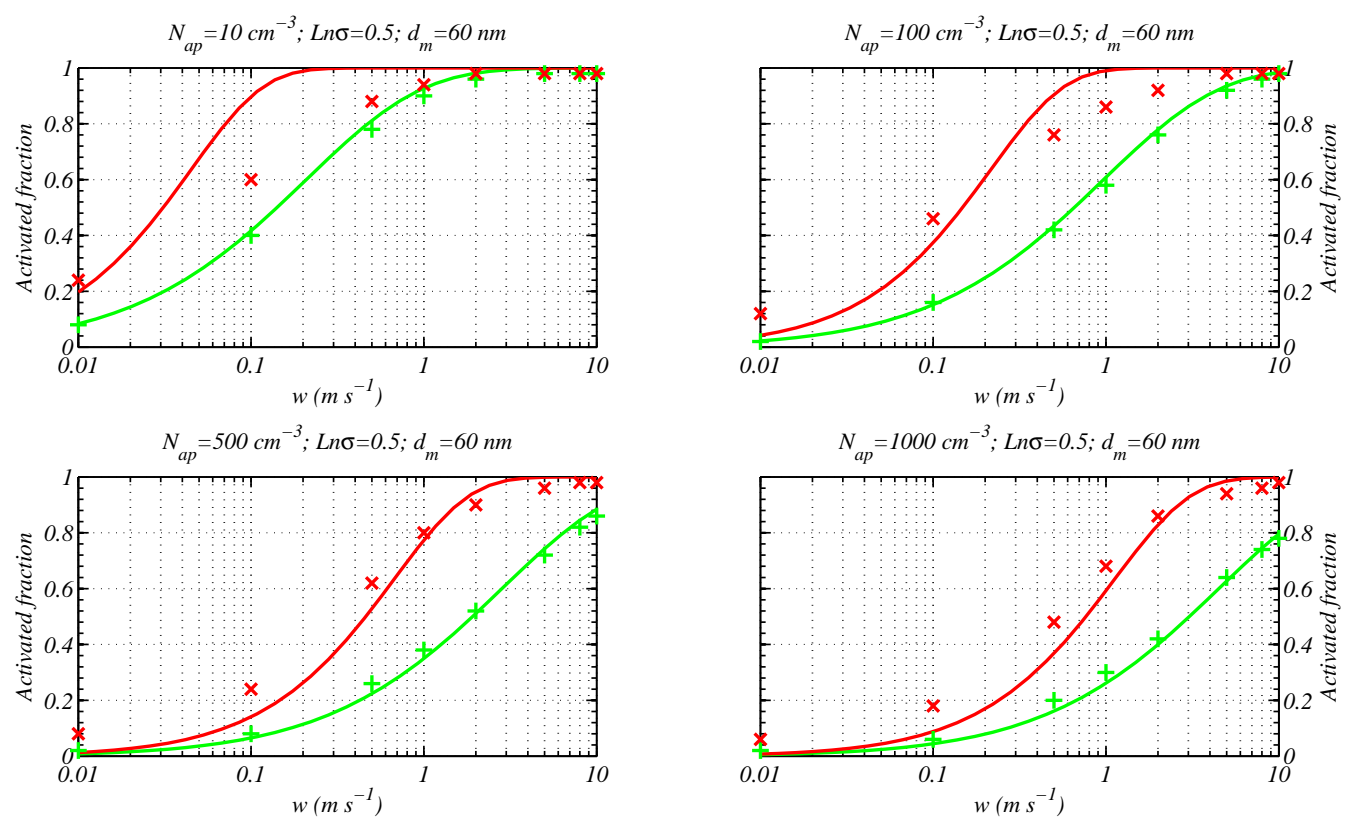

Fig. 7. Same as for the dashed lines in Fig. 6 but with the "core" aerosol size distribution composition set to $90 \%$ semi-volatile: total (by mass).

particle concentrations equal to 500 and $1000 \mathrm{~cm}^{-3}$, but that for lower concentrations, the parameterisation with cocondensation tends to overestimate the activated fraction (for low to high updrafts). The reason for this is evident from Fig. 3, which shows that the fraction condensed, at cloud base, in the highest volatility bins moves to values lower than that at equilibrium as the updraft speed increases. Furthermore, in general the lower the aerosol concentration the lower the condensed fraction of semi-volatile organics. It should also be noted from Fig. 3 that, even in the runs with higher aerosol particle concentrations, the condensed fraction decreases as the updraft speed increases; however, at these high updraft speeds the activated fraction approaches unity and so the impact on the activated fraction is marginal.

In order to test the parameterisation over a wider range of conditions we increased the value of $\ln \sigma$ from 0.5 to 0.6. These simulations are shown in Fig. 8. Specifying a broader initial aerosol distribution has the result that the runs without co-condensation show a slightly lower activated fraction for a given updraft speed. This is because the larger aerosol particles take up more water and so impact on the peak super-saturation during the formation of cloud. Interestingly, the runs with co-condensation show that a broader distribution leads to higher activated fractions (the opposite effect). The reason for this is because we specify a $90 \%$ by mass semi-volatile content in the initial aerosol. This specification means that the total semi-volatile mass loading is higher in the runs with the broader mode, which results in a larger increase in the size of the aerosol particles at cloud base (compared to the narrower-mode runs with co-condensation).
Both of these effects are reproduced to some extent with the parameterisation. It should be recognised that this specification of $90 \%$ by weight of semi-volatile organics in the aerosol is the reason we observe an increase in the activated fraction, for the runs with a broader distribution compared to the narrow distribution, in runs with co-condensation.

We also performed a set of runs with $d_{\mathrm{m}}=120 \mathrm{~nm}$, as shown in Fig. 9. As expected, the activated fraction is higher than for the $60 \mathrm{~nm}$ median diameter runs and the agreement between parcel model and parameterisation is arguably better than for the smaller median diameter runs. The reason for this is that the larger particle median diameters results in a higher fraction of semi-volatiles being condensed at cloud base that is also closer to the equilibrium mass loading (see Fig. 3). The agreement is not as good at low updraft speeds, with the parameterisation tending to underestimate the activated fraction. These discrepancies may be due to deficiencies in the original activation scheme.

\subsection{Application to model-derived updraft PDFs}

The purpose of this section is to show how the schemes behave for distributions of updraft velocities that are atmospherically relevant. In order to achieve this, a probability density function (PDF) of the updraft velocity at cloud base for idealised trade wind $\mathrm{Cu}$ based on data from the Rain In Cumulus over the Oceans (RICO) experiment (vanZanten et al., 2011).

The case in question is a shallow, marine $\mathrm{Cu}$ case in the trades over the western Atlantic. The domain size extends over a $256 \times 256$ horizontal grid with a resolution of $100 \mathrm{~m}$. 

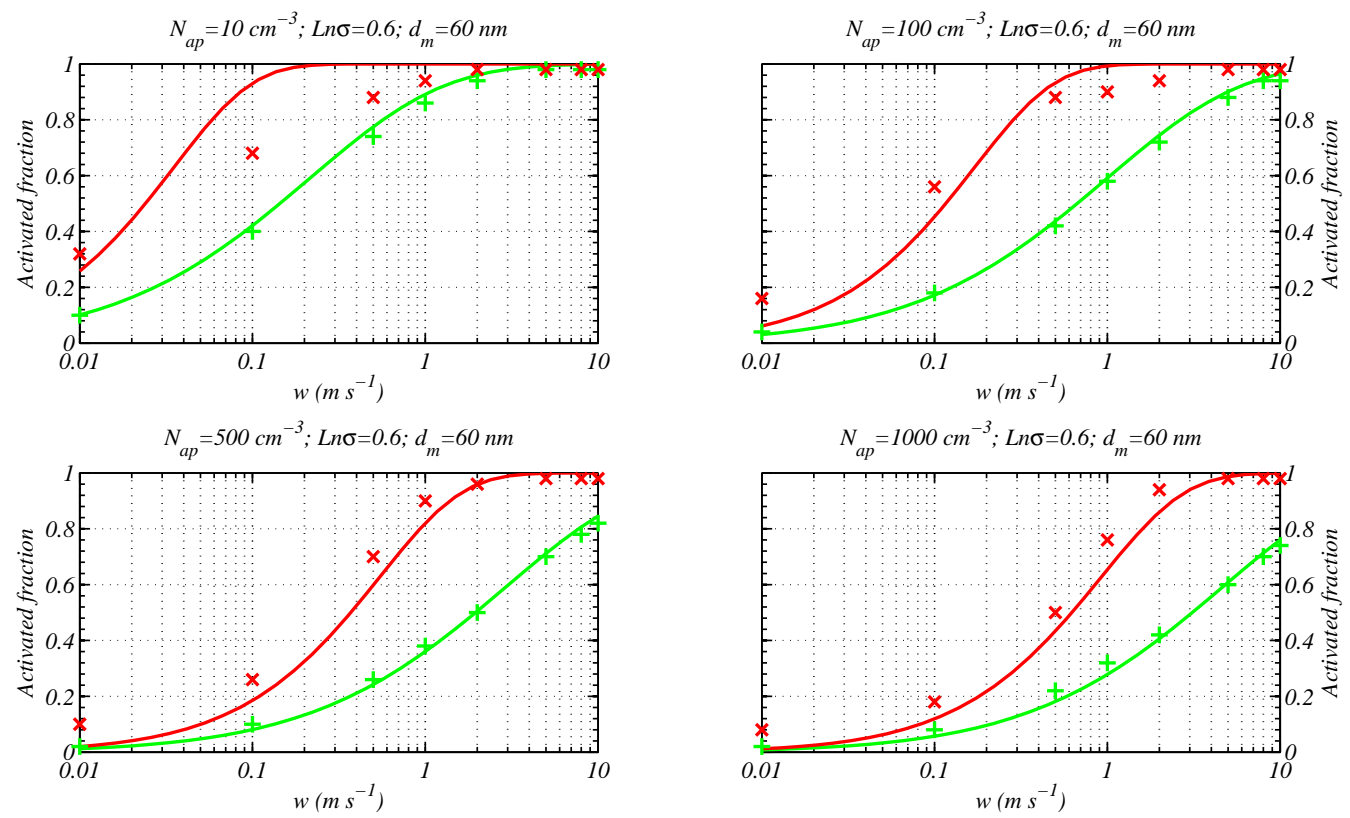

Fig. 8. Same as Fig. 7 but for a broader distribution (ln $\sigma$ changed from 0.5 to 0.6$)$.
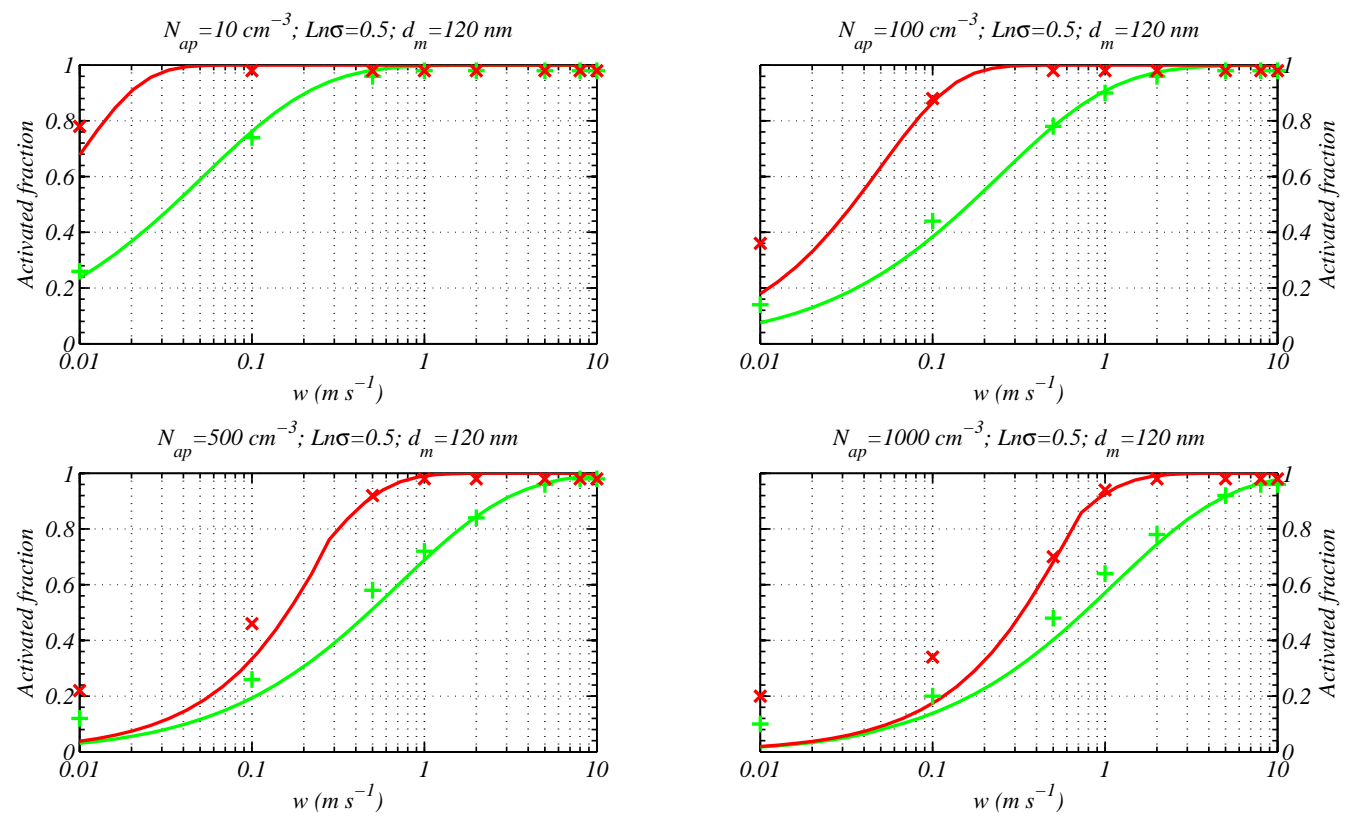

Fig. 9. Same as Fig. 7 but for a larger median diameter.

The vertical grid consists of 100 layers on a stretched grid and uses a spacing of $40 \mathrm{~m}$ in the boundary layer, increasing to $100 \mathrm{~m}$ in the mid-troposphere up to $7 \mathrm{~km}$. It is then further reduced in resolution to $200 \mathrm{~m}$ towards to top of the domain, which is at $10 \mathrm{~km}$. The vertical velocity at grid points entering the cloud base were sampled from the model and are shown in Fig. 10. This shows a mode updraft speed at cloud base of $\sim 0.3 \mathrm{~m} \mathrm{~s}^{-1}$, which is negatively skewed, with peak updrafts extending up to around $\sim 1.5-2.0 \mathrm{~m} \mathrm{~s}^{-1}$.
We generated a histogram of activated fractions for the PDF of updrafts shown in Fig. 10 by randomly sampling $w_{\mathrm{cb}}$ base on its probability of occurrence, using a sample size of 100000 . The activated fraction was calculated using the parameterisation scheme based on the second type of initialisation (see Sect. 2.2.2) using the schemes of either AbdulRazzak et al. (1998) or Fountoukis and Nenes (2005) for both with and without semi-volatile co-condensation. The nonvolatile aerosol size distribution assumed in this comparison 


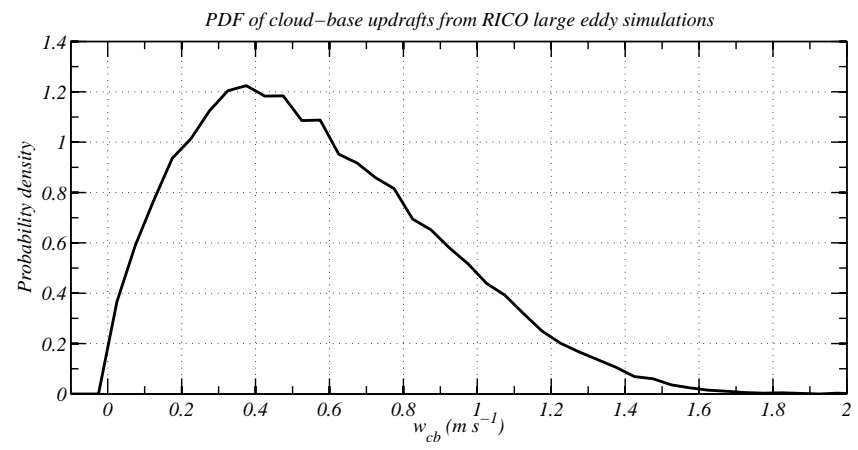

Fig. 10. The PDF of updraft velocities derived from RICO. This is presented as a probability density, where $\int_{0}^{\infty} P d w_{\mathrm{cb}}=1$.

was lognormal with $N_{\text {ap }}=1000 \mathrm{~cm}^{-3}, \ln \sigma=0.5$ and $d_{\mathrm{m}}=$ $60 \mathrm{~nm}$.

Figure 11 shows cumulative frequencies $\left(n=10^{5}\right)$ of the activated fraction for the parcel model runs: the Fountoukis and Nenes (2005) implementation of the scheme and the Abdul-Razzak et al. (1998) implementation. The figure shows that addition of semi-volatile co-condensation broadens the range of activated fractions and, importantly, leads to a much higher frequency at higher activated fractions (as noted by the fact that the cumulative frequency is close to unity at lower activated fractions).

Relative to the parcel model it is also evident that both parameterisation schemes have higher frequencies at low activated fractions, which is due to them underestimating the activated fractions at low updraft speeds (see Figs. 6, 7, 8 and 9 especially). It is evident that the Abdul-Razzak et al. (1998) implementation of the scheme has much higher frequencies than the parcel model at activated fractions less than $\sim 0.1$, which is due to the scheme underestimating the activated fraction at low updraft speeds (e.g. Fig. 6, solid lines) and partially due to the rather sharp crossover at low updraft speeds (Fig. 6, solid lines), where switching on semivolatile co-condensation results in less droplets activating in the Abdul-Razzak et al. (1998) scheme, but not in the parcel model. This effect is much less evident in the Fountoukis and Nenes (2005) implementation of the scheme (Fig. 11, centre plot) and both the mean and standard deviation are much closer to those from the parcel model.

The over estimation of low activated fractions in the Abdul-Razzak et al. (1998) scheme results in a significant underestimation of the mean activated fraction when semivolatile co-condensation is switched on (by almost a factor of 2), whereas the Fountoukis and Nenes (2005) implementation is much closer to the parcel model.

\section{Discussion}

In the development of a parameterisation for activation of aerosols that includes the effect of condensation of organ- ics, we had to make assumptions for how much of the semivolatile condenses onto the aerosol at cloud base; following which we used this constraint as a basis for an "equivalent dry" aerosol size distribution to be input into the existing activation schemes. It was found by running a detailed parcel model that, at low updraft speed, high aerosol particle concentrations and large median diameters, diffusion of the organic vapour to the aerosol was fast enough to stay close to equilibrium. At higher updraft speeds and low total aerosol number concentrations diffusion was too slow and resulted in significant concentrations of organic vapour above cloud base. Hence, we cannot strictly assume that the organic vapour content is in equilibrium at cloud base. However, because high updraft speeds and low aerosol numbers tend to result in high activated fractions, the reduced condensed organic mass loading appears to not factor significantly. This is because, even without the addition of organic material, nearly all of the aerosol activate at such high updraft speeds.

It is evident that the Fountoukis and Nenes (2005) scheme performs better in this comparison; however, at low updraft speeds it still underestimates the activated fraction when compared to the parcel model. This effect happens more readily for high aerosol number concentrations. The reason for this is that at the point of activation the aerosol size distribution splits into those that remain interstitial and those that become activated into cloud drops. The large difference in size means that organic vapours will condense preferentially onto the largest particles in the size distribution rather than be distributed equally over the whole size distribution, as we have assumed for the parameterisation. At present it is difficult to devise a way of overcoming this problem.

Xu and Penner (2012, Sect. 5.2) describe a method for redistributing the mass of nitric acid to the fine-mode aerosol such that the Abdul-Razzak et al. (1998) scheme can be used to calculate the activated fraction. Our method is similar, but goes a step further in redistributing the mass of condensed semi-volatile organics in such a way that is consistent with parcel model simulations. The parcel model simulations showed that the effect of condensation of organic vapours onto the aerosol size distribution served to increase the "dry" diameter of all particles by an approximately constant factor. This resulted in the arithmetic standard deviation remaining relatively constant and hence a reduction in the geometric standard deviation (as the geometric diameter increased). The physical basis for all sizes being increased by an approximately constant factor following co-condensation is that the true particle sizes are all quite similar as they consist mainly of water. This results in a constant diameter growth (see Appendix). Taking into account the fact that the arithmetic standard deviation did not change appreciably was crucial to accurately predicting the activated fraction (Sect. 2.2.3).

It is recognised that there may be other important factors to consider in such a parameterisation, including mass accommodation coefficients, entrainment rates and multiple aerosol modes (as was considered by Ghan et al., 2011). 

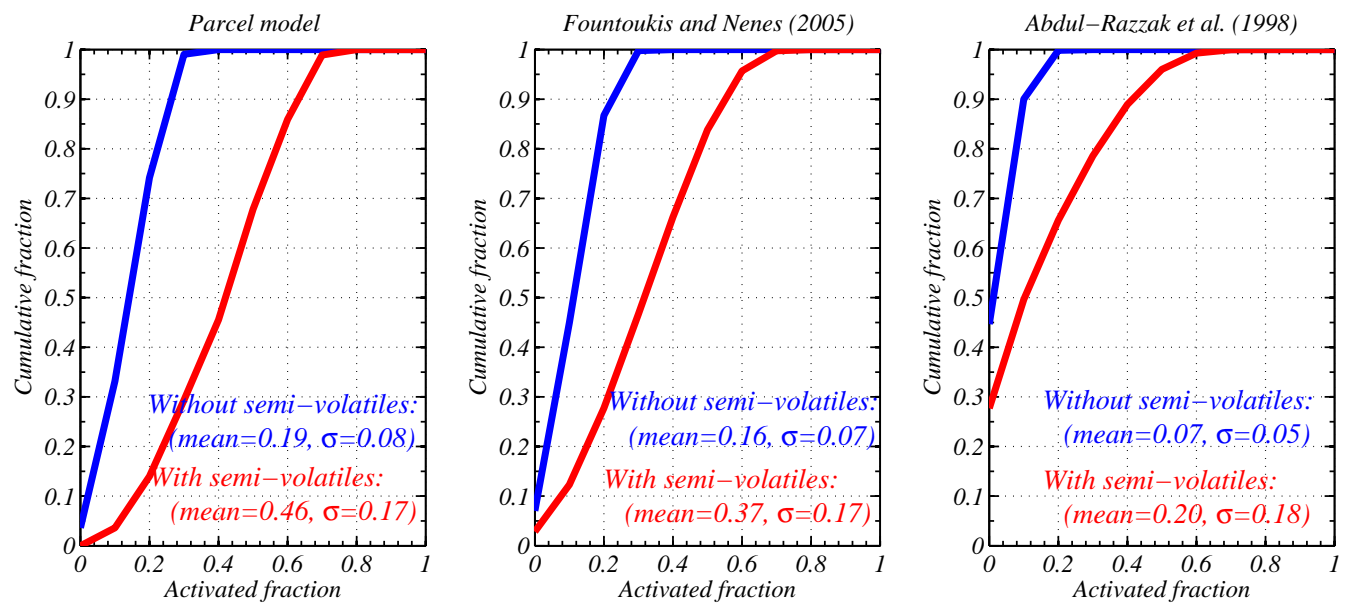

Fig. 11. Cumulative frequency of activated fraction for (i) parcel model simulations (left), Fountoukis and Nenes (2005) implementation (centre) and Abdul-Razzak et al. (1998) implementation (right). Blue is without semi-volatile co-condensation; red is with.

Nevertheless, owing to the fact that the parameterisations used are physically based, such factors can be taken into account in both representations. The additions derived herein that take in to account the effect of semi-volatiles do not prevent the inclusion of these effects.

\section{Conclusions}

A parameterisation for aerosol activation including semivolatile co-condensation has been developed for use in largescale models that carry representations of organic vapour concentrations of different volatilities. It is based on the schemes described by Abdul-Razzak et al. (1998) and Fountoukis and Nenes (2005). The main addition is in the shifting of both the median diameter and the standard deviation of the non-volatile aerosol lognormal distribution. Although this paper presented calculations for a single lognormal mode, this can be extended to multiple lognormal modes, as has been shown previously. One difficulty to overcome is how to partition the organic mass to each mode. In order to be consistent with the ideas presented in this paper, the inclusion of multi-modal aerosol in the co-condensation parameterisation would require that the median diameter of each mode be shifted by the same amount and that the arithmetic standard deviation of each mode remain constant. It is possible to readily implement such a scheme; however, this idea needs to be tested in further work.

The conclusions drawn from the study are as follows:

- Both the geometric diameter and the geometric standard deviation of the "effective dry" aerosol distribution shift during the co-condensation process. The reduction in geometric standard deviation is the main reason why activated fraction increases (see Sect. 2.2.3).
- For the updrafts tested, the inclusion of cocondensation results in a broadening of the distribution of activated fractions. It is evident that the AbdulRazzak et al. (1998) implementation of the scheme significantly underestimates the mean activated fraction when compared to the parcel model and Fountoukis and Nenes (2005) scheme, especially when the effect of semi-volatiles is included.

- However, the Abdul-Razzak et al. (1998) scheme also seems to overestimate the frequency of low activated fractions even without the inclusion of semi-volatiles (Fig. 11, green lines).

- It appears, at least for the conditions tested herein, that the Fountoukis and Nenes (2005) scheme performs better than the Abdul-Razzak et al. (1998) scheme when compared to the parcel model approach. This is especially evident at low updraft speeds (Fig. 6).

- When initialising so that the initial aerosol size distribution has the specified lognormal parameters, it is evident that the parameterisation over estimates the activated fraction for low aerosol particle number concentrations. The reason is that the more volatile organic vapours do not have time to condense before reaching cloud base.

Acknowledgements. We acknowledge funding from the Natural Environment Research Council (NERC) programme "AerosolCloud Interactions - a Directed Programme to Reduce Uncertainty in Forcing" (ACID-PRUF), grant code NE/I020121/1, and the EU FP7-ENV-2013 programme "impact of Biogenic versus Anthropogenic emissions on Clouds and Climate: towards a Holistic UnderStanding" (BACCHUS), project number 603445. The Met. Office (Steve Abel) are acknowledged for providing the data 
for the PDF of updrafts in Fig. 10. The authors would like to thank reviewer Ari Laaksonen for his commentary and encouragement to ensure our parameterisation is robust and general. A Fortran 90 code of the parameterisation described in the paper is available on request from the University of Manchester authors.

Edited by: A. Nenes

\section{References}

Abdul-Razzak, H., Ghan, S. J., and Rivera-Carpio, C.: A parameterization of aerosol activation. 1. Single aerosol type, J. Geophys. Res., 103, 6123-6131, 1998.

Albrecht, B. A.: Aerosols, cloud microphysics and fractional cloudiness, Science, 245, 1227-1230, 1989.

Cappa, C. D. and Jimenez, J. L.: Quantitative estimates of the volatility of ambient organic aerosol, Atmos. Chem. Phys., 10, 5409-5424, doi:10.5194/acp-10-5409-2010, 2010.

Charlson, R. J., Lovelock, J. E., Andreae, M. O., and Warren, S. G.: Ocean phytoplankton, atmospheric sulphur, cloud albedo and climate, Nature, 326, 655-661, 1987.

Fountoukis, C. and Nenes, A.: Continued development of a cloud droplet formation parameterization for global climate models, J. Geophys. Res., 110, doi:10.1029/2004JD005591, 2005.

Ghan, S. J., Abdul-Razzak, H., Nenes, A., Ming, Y., Xiaohong, L., Ovchinnikov, M., Shipway, B., Meskhidze, N., Xu, J., and Shi, X.: Droplet nucleation: Physically-based parameterizations and comparative evaluation, J. Adv. Model. Earth Syst., 3, M10001, doi:10.1029/2011MS000074, 2011.

Kulmala, M., Suni, T., Lehtinen, K. E. J., Dal Maso, M., Boy, M., Reissell, A., Rannik, Ü., Aalto, P., Keronen, P., Hakola, H., Bäck, J., Hoffmann, T., Vesala, T., and Hari, P.: A new feedback mechanism linking forests, aerosols, and climate, Atmos. Chem. Phys., 4, 557-562, doi:10.5194/acp-4-557-2004, 2004.

McFiggans, G. B., Topping, D. O., and Barley, M. H.: The sensitivity of secondary organic aerosol component partitioning to the predictions of component properties - Part 1: A systematic evaluation of some available estimation techniques, Atmos. Chem. and Phys., 10, 10255-10272, doi:10.5194/acp-10-10255-2010, 2010.
Romakkaniemi, S., Kokkola, H., and Laaksonen, A.: Parameterisation of the nitric acid effect on CCN activation, Atmos. Chem. Phys., 5, 879-885, doi:10.5194/acp-5-879-2005, 2005.

Solomon, S., Qin, D., Manning, M., Chen, Z., Marquis, M., Averyt, K. B., Tignor, M., and Miller, H. L.: IPCC, 2007: Climate Change 2007: The Physical Science Basis. Contribution of Working Group 1 to the Fourth Assessment Report of the Intergovernmental Panel on Climate Change, http://www.ipcc.ch/pdf/ assessment-report/ar4/wg1/ar4-wg1-spm.pdf, 2007.

Topping, D. O. and McFiggans, G. B.: Tight coupling of particle size, number and composition in atmospheric cloud droplet activation, Atmos. Chem. Phys., 12, 3253-3260, doi:10.5194/acp12-3253-2012, 2012.

Topping, D. O., Connolly, P. J., and McFiggans, G. B.: Cloud droplet number enhanced by co-condensation of organic vapours, Nature Geosci., 6, 443-446, doi:10.1038/NGEO1809, 2013.

Twomey, S.: The nuclei of natural cloud formation: the supersaturation in natural clouds and the variation of cloud droplet concentration, Geofis pura et appl., 43, 243-249, 1959.

Twomey, S.: The influence of pollution on the shortwave albedo of clouds, J. Atmos. Sci., 34, 1149-1152, 1977.

vanZanten, M. C., Stevens, B. B., Nuijens, L., Siebesma, A. P., Ackermann, A. S., Burnet, F., Cheng, A., Couvreux, F., Jiang, H., Khairoutdinov, M., Kogan, Y. L., Lewellen, D. C., Mechem, D., Nakamura, K., Noda, A., Shipway, B. J., Slawinska, J., Wang, S., and Wyszogrodzki, A.: Controls on precipitation and cloudiness in simulations of trade-wind cumulus as observed during RICO, J. Adv. Model. Earth Syst., 3, M060001, doi:10.1029/2011MS000056, 2011.

$\mathrm{Xu}$, L. and Penner, J. E.: Global simulations of nitrate and ammonium aerosols and their radiative effects, Atmos. Chem. Phys., 12, 9479-9504, doi:10.5194/acp-12-9479-2012, 2012. 


\section{Appendix A}

\section{Why does the aerosol distribution not narrow with condensing organics?}

To answer this question, we assume the growth from the organic vapour of an aerosol particle that is an internal mixture of an involatile component and $N$ semi-volatile components.

The well-known Maxwellian growth theory shows that such a particle will increase in diameter at a rate inversely proportional to its diameter:

$\frac{d d}{d t} \propto \frac{1}{d}$,

where $d$ is the diameter of the particle.

In the case of co-condensing organics it should be noted that, at the high humidities relevant for cloud formation, the particle consists mostly of water. Condensing water onto the particles results in a narrowing of the ratio of droplet diameters in a distribution (as predicted by both Maxwellian growth, $\frac{d d}{d t} \propto \frac{1}{d}$, and sub-saturated aerosol growth, $\frac{d d}{d t} \propto$ constant); thus near cloud base, the droplet size distribution consists of a narrow ratio of droplet diameters.

The narrow distribution means we can approximate the term $\frac{1}{d}$ on the right-hand side of Eq. (A1) to be a constant. Note that this is only the case for the condensing organics, not condensing water vapour. In this situation we arrive at the result that, regardless of the initial particle size, the difference in particle size after co-condensation of organics is proportional to $t$. Therefore, if all particles experience the same growth time, their change in size will be a constant:

$d_{2}-d_{1} \propto t$

where $d_{1}$ and $d_{2}$ are the initial and final particle diameters respectively.
However, it should be noted that the diameters considered in Eqs. (A1) and (A2) are the true physical diameters of the drop, whereas for the parameterisation outlined in this paper we require the "dry" particle size. We now show, to a first approximation, that at cloud base the "dry" particle size is directly related to the wet particle size.

Firstly we assume that, to a first approximation, the physical diameter is proportional to the cubed root of the sum of the number of moles of each component (strictly, it is actually the volume of the sum of each component). Therefore we can rewrite Eq. (A2) as

$\left(n_{c}+n_{\mathrm{w}, 2}+\sum n_{i, 2}\right)^{1 / 3}-\left(n_{\mathrm{c}}+n_{\mathrm{w}, 1}+\sum n_{i, 1}\right)^{1 / 3} \propto t$,

where $n_{\mathrm{i}}$ is the number of moles of component $i$ in the condensed phase, $n_{c}$ is the number of moles of the involatile component (e.g. ammonium sulfate) and $n_{\mathrm{w}}$ is the number of moles of water.

Raoult's law for water vapour in equilibrium at relative humidity, $\mathrm{RH}_{\mathrm{eq}}$, with an aerosol particle is

$\mathrm{RH}_{\mathrm{eq}}=\frac{n_{\mathrm{w}}}{n_{\mathrm{c}}+n_{\mathrm{w}}+\sum n_{i}}$,

which can be rearranged to make $n_{\mathrm{w}}$ the subject:

$n_{\mathrm{w}}=\frac{\mathrm{RH}_{\mathrm{eq}}}{1-\mathrm{RH}_{\mathrm{eq}}}\left(n_{\mathrm{c}}+\sum n_{\mathrm{i}}\right)$.

Hence, at equilibrium, the number of moles of water is proportional to the number of moles of all other components. Equation (A5) can then be substituted into Eq. (A3) with the result that the change in particle "dry" diameter is approximately constant for all sizes in the distribution. 